\title{
Stability and Blowout Behavior of Jet Flames in Oblique Air Flows
}

\author{
Jonathan N. Gomes, James D. Kribs, and Kevin M. Lyons \\ Department of Mechanical and Aerospace Engineering, North Carolina State University, Raleigh, NC 27695-7910, USA \\ Correspondence should be addressed to Kevin M. Lyons, lyons@eos.ncsu.edu
}

Received 1 December 2011; Revised 23 March 2012; Accepted 1 April 2012

Academic Editor: Tarek Echekki

Copyright ( $) 2012$ Jonathan N. Gomes et al. This is an open access article distributed under the Creative Commons Attribution License, which permits unrestricted use, distribution, and reproduction in any medium, provided the original work is properly cited.

\begin{abstract}
The stability limits of a jet flame can play an important role in the design of burners and combustors. This study details an experiment conducted to determine the liftoff and blowout velocities of oblique-angle methane jet flames under various air coflow velocities. A nozzle was mounted on a telescoping boom to allow for an adjustable burner angle relative to a vertical coflow. Twentyfour flow configurations were established using six burner nozzle angles and four coflow velocities. Measurements of the fuel supply velocity during liftoff and blowout were compared against two parameters: nozzle angle and coflow velocity. The resulting correlations indicated that flames at more oblique angles have a greater upper stability limit and were more resistant to changes in coflow velocity. This behavior occurs due to a lower effective coflow velocity at angles more oblique to the coflow direction. Additionally, stability limits were determined for flames in crossflow and mild counterflow configurations, and a relationship between the liftoff and blowout velocities was observed. For flames in crossflow and counterflow, the stability limits are higher. Further studies may include more angle and coflow combinations, as well as the effect of diluents or different fuel types.
\end{abstract}

\section{Introduction}

A multitude of studies have been performed on lifted jet flames and their behavior in various air flow configurations. In such partially premixed flames, the characteristics of the surrounding air flow (velocity, temperature) can strongly impact the overall combustion process and the stability parameters. As fuel flows from a nozzle and mixes with the air, the fuel and oxidizer concentrations vary throughout space and time. The extent of mixing due to turbulence also changes depending on the surrounding flow. The perpetually varying concentrations help to determine the overall behavior of a flame: its shape, velocity, size, color, temperature, and composition. In parallel, the heat release serves to laminarize regions and serves to limit reducing mixing.

In particular, two important behavioral parameters are liftoff and blowout velocity. Initially, a jet flame will remain attached to the nozzle at low fuel velocities. However, at a critical jet velocity, the flame will lift off from the nozzle and stabilize at a position downstream due to the inability of the flame to remain anchored on the burner [1]. While there is, in general, a regime where the flame can stabilize, increasing the jet velocity will ultimately lead to blowout, in which the flame is extinguished. This behavior occurs at some critical blowout velocity. Together, the liftoff and blowout velocities essentially define the stability limits of a lifted jet flame.

Typically, past experiments on liftoff and blowout have focused on coaxial flow. In this arrangement, the jet nozzle is parallel to a surrounding airflow (coflow). Another common arrangement is transverse flow, in which the nozzle is perpendicular to the airflow (crossflow). Jet diffusion flames behave differently in both arrangements, as previously performed experiments have demonstrated.

Early major experiments involving flame stability in coflow were conducted by Wohl et al. around 1950 [2]. They determined that the liftoff and blowout velocities (stability limits) are functions of the supply (jet) velocity and fuel concentration. When the supply velocity is less than the flame velocity, then the flame will flash back into the burner. In contrast, the flame will lift off from the burner and equilibrate downstream when the supply velocity exceeds a critical value. Later, Vanquickenborne and Van Tiggelen [3] expanded on Wohl by suggesting that the liftoff height occurs 
where the mean incoming fuel velocity equals the turbulent burning velocity of the flame (induced under coflow). Their work has served as the foundation for other experiments involving the modeling of jet diffusion flames.

Another major development occurred in 1984 with the work of Kalghatgi [4], who built on the previous work of Vanquickenborne and Van Tiggelen. He observed that the flame liftoff height for hydrogen, propane, methane, and ethylene depends on several physical parametersand strongly on the jet exit velocity. A linear correlation exists between the two variables, regardless of the burner diameter. After performing a nondimensional analysis of his data, Kalghatgi concluded that diffusion flames blow out at a height, that is, 0.65-0.75 times the height of the stoichiometric contour. According to his findings, the height is also inversely proportional to the square of the laminar burning velocity.

Brown et al. have studied the effect of jet exit velocity and coflow velocity on liftoff height [5]. They discovered that the former has a minimal effect on lifted flames that are significantly downstream from the burner exit (i.e., in the far field). In this area, the turbulent burning velocity equals the flame stabilization velocity. However, in the near field relative to the burner, findings reveal that the stabilization velocity is approximately equal to three times the laminar burning velocity.

The work of Vanquickenborne and van Tiggelen also formed the basis for a study by Tieszen et al. which explored blowout mechanisms [6]. Their results confirmed the theory proposed by Vanquickenborne and van Tiggelen: blowout occurs when the local flow velocity exceeds the turbulent burning speed of the flame. However, they also investigated the role of large-scale eddies, concluding that they are responsible for flame propagation in the interior of the jet. Burgess and Lawn [7] have expanded on the work of Vanquickenborne and van Tiggelen by including the effects of large eddy structures and locations where the flame is relatively stable. Imaging and direct numerical simulations revealed that flames tend to propagate near large eddies, but away from the center where the mixture is too rich. In addition, Navarro-Martinez and Kronenburg [8] have consolidated results from large eddy simulations (LESs) for multiple lifted flame configurations. They assert that the conditional moment closure approach can accurately predict stability conditions based on experimental behavior. Recently, more studies have focused on modeling and simulating jet flames using LES and other techniques.

While jet behavior in coflow has been extensively studied, less attention has been devoted to jets in crossflow. In a review, Bandaru and Turns included a comprehensive list of all major crossflow research to date [9]. Many of the works relevant to this study were observation-based experiments performed by Kalghatgi, whose crossflow flame experiments were conducted in a wind tunnel and involved propane, methane, and ethylene fuels. In parallel with the research on flame liftoff height in coflow, Kalghatgi investigated flames in a cross-wind normal to the burner axis [10]. His findings revealed two distinct blowout limits for flames in a moderate cross-wind: a lower limit in which the incident wind extinguishes the flame and an upper limit in which the flame blows itself out. At the lower limit, the jet velocity is much lower than the blowout velocity of a jet in still air. However, at the upper limit, the blowout mechanism is similar to that of a flame in still air. The upper blowout limit is usually greater than the blowout velocity in still air due to greater levels of turbulence caused by the cross-wind. Kalghatgi's experimental results demonstrated that a lifted, stable flame can exist between the upper and lower blowout limits.

Kalghatgi also investigated the effect of burner orientation to wind direction [11]. Burner diameters ranged from $4 \mathrm{~mm}$ to $20 \mathrm{~mm}$, while the angle between the wind direction and burner axis varied between $45^{\circ}, 66^{\circ}, 90^{\circ}, 114^{\circ}$, and $135^{\circ}$. By measuring the jet velocity at which blowout occurs (at the lower limit), Kalghatgi concluded that jet flames are less prone to blowout as the burner angle increases from $0^{\circ}$ to $180^{\circ}$. He also discovered that the lower blowout limit does not always exist under low wind speeds. In such conditions, a flame will stabilize in the wake of the burner and the wind cannot extinguish it, especially at angles greater than $90^{\circ}$. Thus, flame behavior is difficult to predict in these conditions.

In another study, Han and Mungal observed the mixing and combustion processes of jet flames injected at $-45^{\circ}, 0^{\circ}$, and $45^{\circ}$ [12]. Using particle image velocimetry (PIV) and $\mathrm{CH}$ PLIF imaging techniques, they concluded that flame length increases with injection angle due to reduced entrainment. They also attempted to model the dilation behavior of the stoichiometric contour, which they suggest occurs due to the premixed characteristics of deflected jet flames. Hasselbrink and Mungal performed a similar study in which the velocity fields of transverse $\left(0^{\circ}\right)$ jet flames were measured using PIV [13]. Overall, they noted greater flame/flow interaction near the base of the lifted flame than at downstream locations.

The purpose of this experiment is to delineate flame stability and blowout behavior at several oblique angles under various flow velocity ratios. Despite a much smaller scale, understanding the behavior of angled flames in an experimental setting can aid in the proper design of flaring towers and burners that account for varying wind conditions, as well as assess conditions in low-turndown industrial burners. By consolidating the overall results, an optimal burner configuration may be chosen based on desired stability and blowout parameters, as well as a relationship between the flame liftoff velocity and blowout.

\section{Experimental Arrangement}

The apparatus used for angled jet experiments is shown in Figure 1. This apparatus was used for previous experiments involving flame stability behavior in coflow and has been described in detail in earlier publications $[14,15]$.

The fuel tube consists of a $3 \mathrm{~mm}$ fuel nozzle that is concentric with a large annulus for air coflow (6 inch). However, this nozzle was not used for angled jet flames. Instead, an appropriate nozzle was devised from $0.25^{\prime \prime}$ $(6.35 \mathrm{~mm})$ stainless steel tubing mounted on a telescoping 


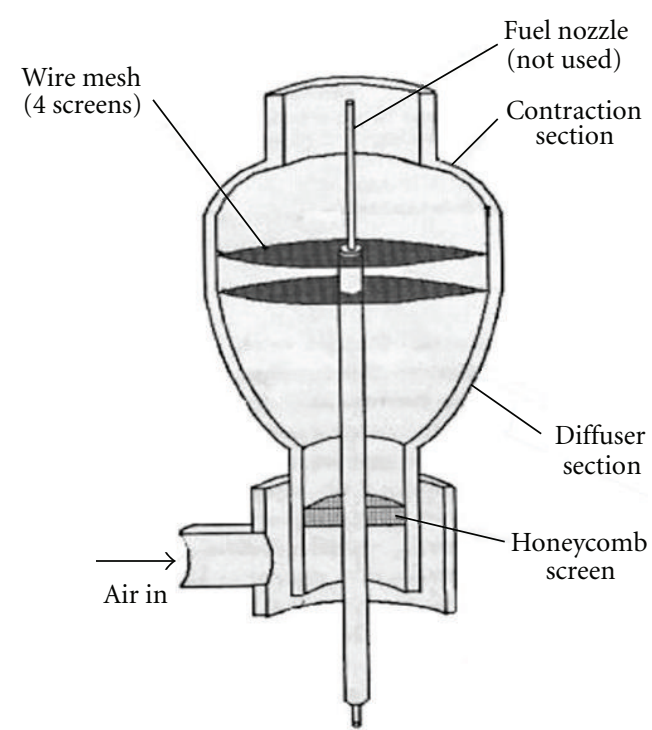

FIGURE 1: Burner apparatus for angled jet experiments.

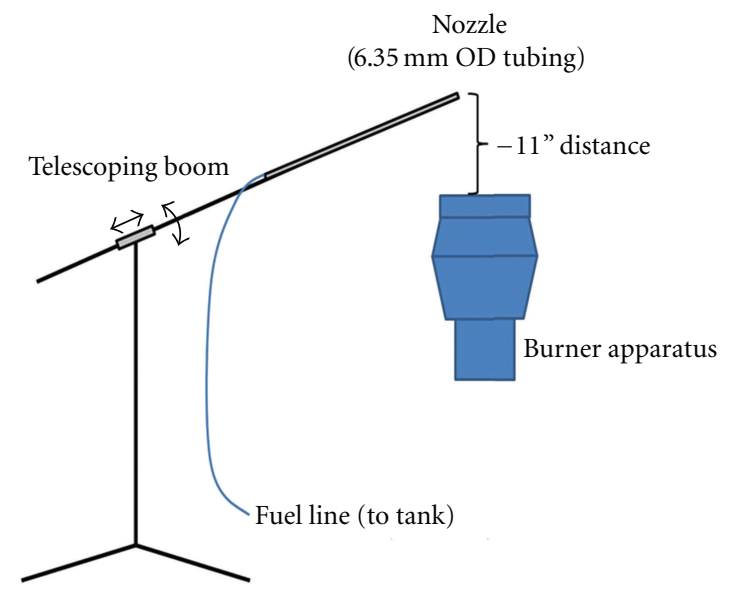

FIgURE 2: Nozzle on telescoping boom.

boom with an adjustable angle, as shown in Figure 2. To determine the angle of the nozzle, a protractor was mounted on the boom. Using a string with a weight at the end (which provided a vertical line of reference), the angle could be read off the protractor. The nozzle is oriented such that it is in the uniform velocity region of the coflow, away from the edges. A vertical distance of 11 inches is maintained between the nozzle and the top of the burner to avoid any irregularities in the air coflow.

The coflow air is pumped by a Magnetek model 9467 centrifugal blower, controlled with a potentiometer to allow for variable operation speeds. The coflow then travels through flexible hose ( 5 inches in diameter) to the burner. The air travels through a $90^{\circ}$ tee before entering a $2.54 \mathrm{~mm}$ thick honeycomb screen. The screen makes the coflow velocity profile more uniform and straight. After the screen, the coflow air enters a diffuser section with a greater crosssection area. The diffuser section contains four wire mesh screens which serve to eliminate flow irregularities and further refine the coflow velocity profile into a "top-hat" shape. Finally, the coflow air exits the burner through a contraction section with a terminating diameter of $150 \mathrm{~mm}$.

The coflow air velocity is measured using a TSI Velocicalc model 8345 hot-wire anemometer, which displayed values in meters per second with a precision of $0.01 \mathrm{~m} / \mathrm{s}$ and an accuracy of $\pm 3 \%$ of the reading. For each coflow velocity measurement, the tip of the wand (containing the sensing element) is placed horizontally on the burner exit, perpendicular to the coflow direction. The potentiometer controlling the blower motor is then adjusted to achieve the desired coflow velocities of $0,0.25,0.40$, and $0.60 \mathrm{~m} / \mathrm{s}$. With the coflow direction constrained to a vertical, upwards flow, it was necessary to adjust the direction of the fuel jet, and this adjustment changed the direction of other forces, such as natural buoyancy. This setup is similar to previous work in oblique flows done by Kalghatgi, by having the coflowing air act in one direction, but varying the angle, at which the fuel jet flows [11]. With the limitation of the size of the coflowing air region, the location of the nozzle and the flame base were important factors. The jet nozzle was maintained at the center of the coflow ring, in order to keep the flame base within the coflow region, which was the main area of interest, as it is the focus of flame stabilization.

The fuel volumetric flow rate is measured using an Advance Series 150 flowmeter, calibrated for use with methane. The flowmeter consists of a stainless steel ball in a graduated cylinder. Readings are taken from the bottom of the ball and converted into units of scfh (standard cubic feet per hour) using the manufacturer's charts. The jet velocity can then be calculated based on the volumetric flow rate and cross-sectional area of the burner. The gas is supplied from a pressurized cylindrical tank and regulated through a MicroLine UHP Gas Panel controller. The speed of the coflowing air was set, as was the angle of nozzle, with regards to the ground. Afterwards, the fuel velocity was gradually increased until liftoff was achieved. The blowout velocity was measured by increasing the jet velocity until the flame approached a meta-stable position, at which the trailing diffusion flame disappears, and the fuel velocity was increased at an incremental pace.

\section{Results and Discussion}

For this experiment, six different angles were chosen: $20^{\circ}$, $30^{\circ}, 40^{\circ}, 50^{\circ}, 60^{\circ}$, and $70^{\circ}$. The $10^{\circ}$ and $80^{\circ}$ angles were not chosen due to their closeness to the $0^{\circ}$ (coflow) and $90^{\circ}$ (crossflow) orientations. At each angle, liftoff and blowout jet velocities were measured under four ambient flow velocities: 0 (still air), $0.25,0.4$, and $0.6 \mathrm{~m} / \mathrm{s}$. (Note: the velocity of 0.25 was chosen due to physical limitations of the blower motor.) Thus, twenty-four flow configurations are established. Table 1 contains the raw data collected for each configuration, along with the calculated values for liftoff and blowout velocity.

As shown by Table 1, the jet velocity is much higher than that of the coflow, ensuring that all flames are jet flames, rather than wake-stabilized flames. For the highest 
TABLE 1: Liftoff and blowout velocities for all flow configurations.

\begin{tabular}{|c|c|c|c|c|c|c|c|}
\hline \multicolumn{2}{|c|}{ Parameters } & \multicolumn{3}{|c|}{ Liftoff } & \multicolumn{3}{|c|}{ Blowout } \\
\hline Angle $\left(^{\circ}\right)$ & $\begin{array}{l}\text { Coflow velocity } \\
(\mathrm{m} / \mathrm{s})\end{array}$ & Meter reading & $\begin{array}{l}\text { Chart value } \\
\left(\mathrm{ft}^{3} / \mathrm{h}\right)\end{array}$ & $\begin{array}{l}\text { Liftoff velocity } \\
(\mathrm{m} / \mathrm{s})\end{array}$ & $\begin{array}{l}\text { Meter } \\
\text { reading }\end{array}$ & $\begin{array}{c}\text { Chart value } \\
\left(\mathrm{ft}^{3} / \mathrm{h}\right)\end{array}$ & $\begin{array}{l}\text { Blowout velocity } \\
(\mathrm{m} / \mathrm{s})\end{array}$ \\
\hline 20 & 0.00 & 43 & 29.9 & 17.22 & 147 & 123.2 & 70.96 \\
\hline 20 & 0.25 & 42 & 29.2 & 16.82 & 140 & 115.8 & 66.70 \\
\hline 20 & 0.40 & 37 & 25.5 & 14.69 & 136 & 111.8 & 64.39 \\
\hline 20 & 0.60 & 32 & 21.7 & 12.50 & 131 & 107.2 & 61.74 \\
\hline 30 & 0.00 & 46 & 32.2 & 18.55 & 145 & 121.0 & 69.69 \\
\hline 30 & 0.25 & 43 & 29.9 & 17.22 & 143 & 118.9 & 68.48 \\
\hline 30 & 0.40 & 40 & 27.7 & 15.95 & 143 & 118.9 & 68.48 \\
\hline 30 & 0.60 & 35 & 24.0 & 13.82 & 139 & 114.8 & 66.12 \\
\hline 40 & 0.00 & 47 & 33.0 & 19.01 & 147 & 123.2 & 70.96 \\
\hline 40 & 0.25 & 42 & 29.2 & 16.82 & 138 & 113.8 & 65.54 \\
\hline 40 & 0.40 & 36 & 24.7 & 14.23 & 137 & 112.8 & 64.97 \\
\hline 40 & 0.60 & 32 & 21.7 & 12.50 & 132 & 108.1 & 62.26 \\
\hline 50 & 0.00 & 47 & 33.0 & 19.01 & 145 & 121.0 & 69.69 \\
\hline 50 & 0.25 & 44 & 30.7 & 17.68 & 148 & 124.3 & 71.59 \\
\hline 50 & 0.40 & 40 & 27.7 & 15.95 & 148 & 124.3 & 71.59 \\
\hline 50 & 0.60 & 33 & 22.5 & 12.96 & 143 & 118.9 & 68.48 \\
\hline 60 & 0.00 & 51 & 36.2 & 20.85 & 150 & 126.4 & 72.80 \\
\hline 60 & 0.25 & 46 & 32.2 & 18.55 & 147 & 123.2 & 70.96 \\
\hline 60 & 0.40 & 47 & 33.0 & 19.01 & 150 & 126.4 & 72.80 \\
\hline 60 & 0.60 & 37 & 25.5 & 14.69 & 150 & 126.4 & 72.80 \\
\hline 70 & 0.00 & 46 & 32.2 & 18.55 & 150 & 126.4 & 72.80 \\
\hline 70 & 0.25 & 47 & 33.0 & 19.01 & 148 & 124.3 & 71.59 \\
\hline 70 & 0.40 & 45 & 31.5 & 18.14 & 143 & 118.9 & 68.48 \\
\hline 70 & 0.60 & 36 & 24.7 & 14.23 & 150 & 126.4 & 72.80 \\
\hline
\end{tabular}

coflow velocity, and the lowest jet velocity, at $20^{\circ}$ with a jet velocity of $12.5 \mathrm{~m} / \mathrm{s}$ and a coflow of $0.60 \mathrm{~m} / \mathrm{s}$, the jet-to-wind momentum flux ratio $(R)$, which compares the momentum of the fuel jet to that of the ambient wind, was calculated to be 241.47, well above $R=10$ needed to define the jet as a strong jet, from Huang and Wang [16].

As expected, the flame shape varied with the angle, with the flame front conforming to the direction of the coflow. The photographs in Figure 3 depict a flame at a $20^{\circ}$ (less oblique) angle, as well as at $50^{\circ}$ and $70^{\circ}$ angles with a coflow velocity of $0.4 \mathrm{~m} / \mathrm{s}$. Three states are shown: the attached flame, the lifted flame, and the hysteresis flame just prior to blowout.

The overall data from Table 1 can be used to form a general stability chart based on the angle between the burner nozzle and coflow air, as shown in Figure 4. Similarly, The data can be consolidated into a general chart based on coflow velocity, as shown in Figure 5.

Based on Figure 4, it can be seen that the flame liftoff velocity is largely resistant to changes in the nozzle angle. The greatest deviation occurs at a coflow velocity of $0.4 \mathrm{~m} / \mathrm{s}$. At each angle, liftoff velocity generally decreases with greater coflow velocity. This behavior can be attributed to the component of the coflow velocity vector that lies parallel to the flame direction. Thus, at greater coflow velocities, a lower fuel supply speed (liftoff velocity) is required for the flame to detach from the burner.

In contrast, the blowout velocities in Figure 4 exhibit greater deviation with increasing coflow velocities. The nozzle angle has a more pronounced effect on blowout velocity under high coflow velocities-namely at 0.40 and $0.60 \mathrm{~m} / \mathrm{s}$. Figure 4 suggests that the blowout velocity increases for higher angles. For the $60^{\circ}$ and $70^{\circ}$ angles, the blowout velocity is over $70 \mathrm{~m} / \mathrm{s}$; however, for the $40^{\circ}, 30^{\circ}$, and $20^{\circ}$ angles, the blowout velocity is between 60 and $65 \mathrm{~m} / \mathrm{s}$. Since the nozzle angle has a minimal effect on the liftoff velocity, it can be concluded that flames have a greater upper stability limit (blowout threshold) at more oblique nozzle angles, namely $60^{\circ}$ and $70^{\circ}$.

The data in Figure 5 exhibits behavior that conforms to the trends shown in Figure 4. Again, it can be observed that liftoff velocity generally decreases under higher coflow velocities for the full range of nozzle angles (but with slightly less deviation at $70^{\circ}$ ). The blowout velocities demonstrate much more variation at smaller angles, with the greatest deviations at $20^{\circ}$ and $40^{\circ}$. However, at $50^{\circ}, 60^{\circ}$, and $70^{\circ}$, the blowout velocities show relatively less deviation. This result indicates that the nozzle angle has a stronger effect on 


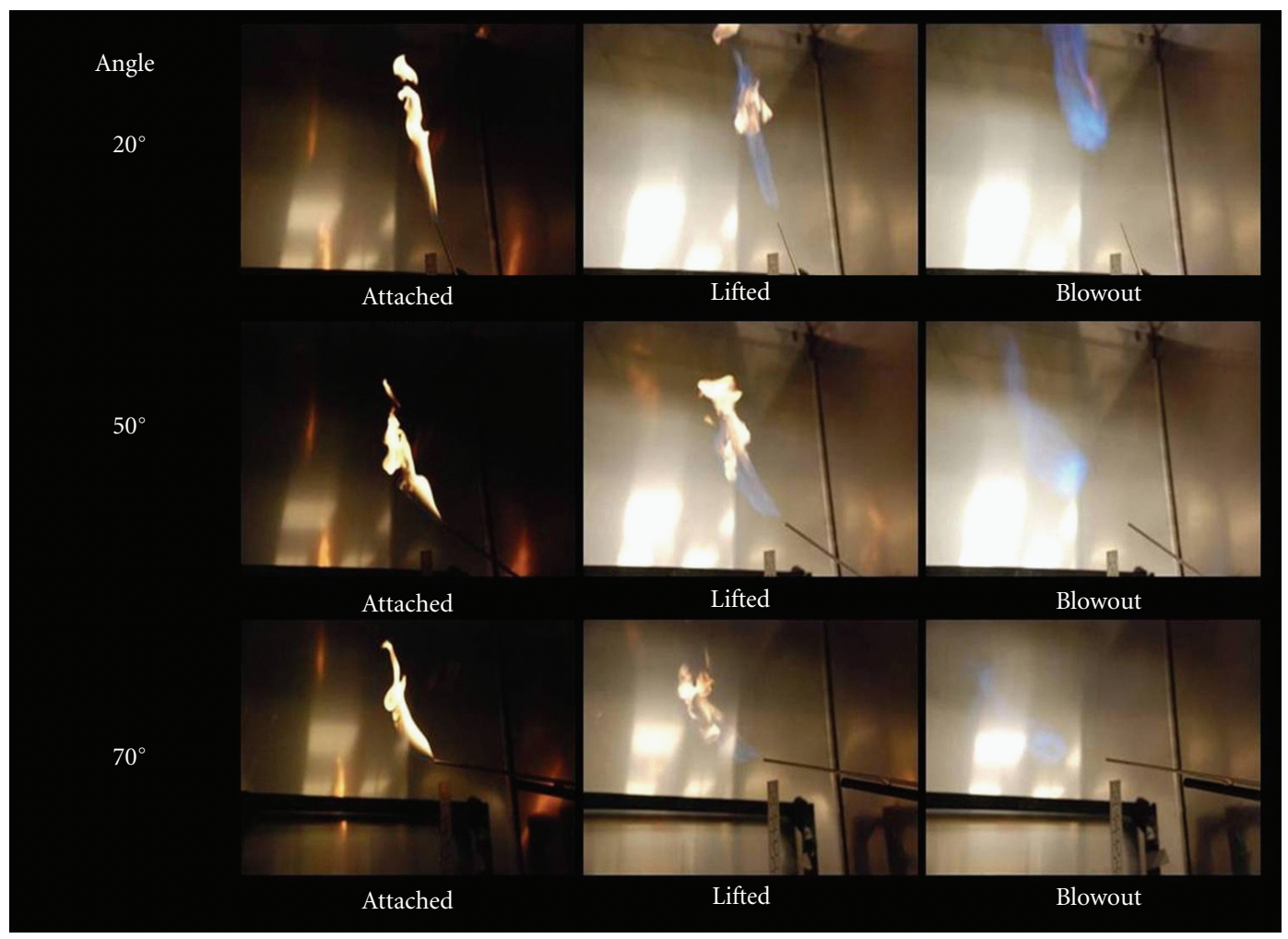

Figure 3: Flame states at $0.4 \mathrm{~m} / \mathrm{s}$ coflow.

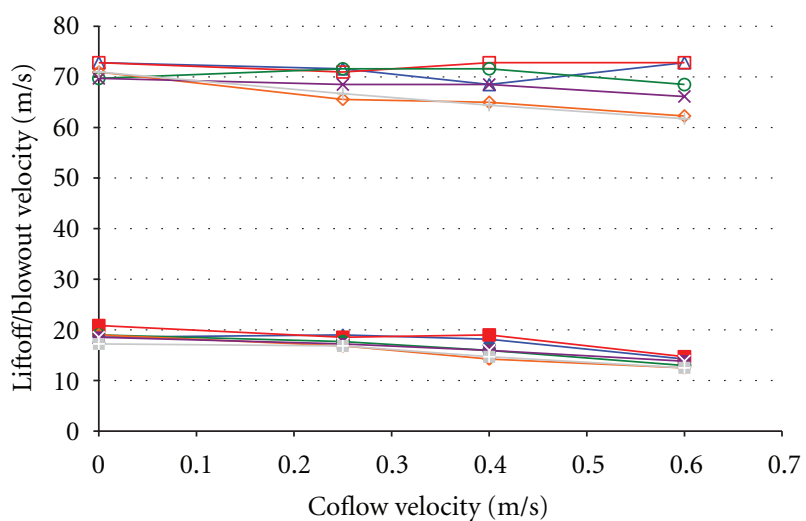

$$
\begin{aligned}
& \neg \operatorname{Liftoff}\left(70^{\circ}\right) \quad \rightarrow \operatorname{Liftoff}\left(40^{\circ}\right) \\
& \triangle \text { Blowout }\left(70^{\circ}\right) \multimap \text { Blowout }\left(40^{\circ}\right) \\
& \rightarrow \operatorname{Liftoff}\left(60^{\circ}\right) \rightarrow \operatorname{Liftoff}\left(30^{\circ}\right) \\
& \square \text { Blowout }\left(60^{\circ}\right) \quad \rightarrow \text { Blowout }\left(30^{\circ}\right) \\
& \rightarrow \operatorname{Liftoff}\left(50^{\circ}\right)-\operatorname{Liftoff}\left(20^{\circ}\right) \\
& \multimap \text { Blowout }\left(50^{\circ}\right) \longrightarrow \text { Blowout }\left(20^{\circ}\right)
\end{aligned}
$$

FIGURE 4: Stability limits versus coflow velocity for all angles.

blowout velocity than the coflow velocity, thus following the behavior shown in Figure 4.

Overall, it can be concluded that flames at more oblique angles $\left(50^{\circ}-70^{\circ}\right)$ have a greater upper stability limit that is also more resistant to changes in coflow velocity. This behavior is due to a reduced coflow velocity component

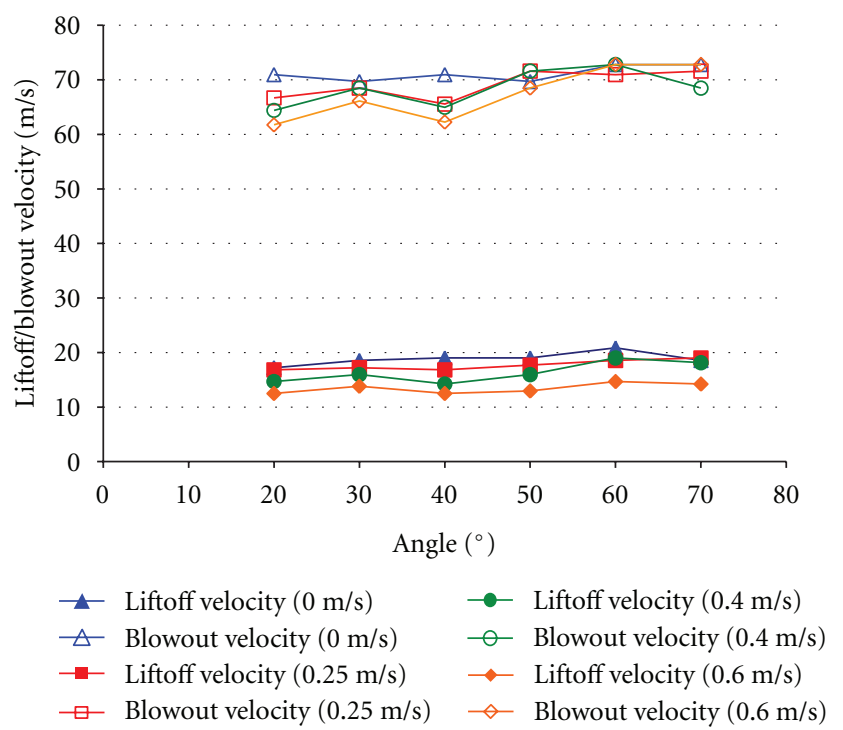

Figure 5: Stability limits versus angle for all coflow velocities.

that approaches zero as the nozzle angle approaches $90^{\circ}$. The effective coflow velocity is the component of the overall coflow velocity vector that lies along the flame/nozzle direction. With the coflow remaining vertical, this component diminishes as the nozzle angle increases towards the horizontal-that is, less of the coflow blows along the flame and contributes to liftoff/blowout behavior. The effective 


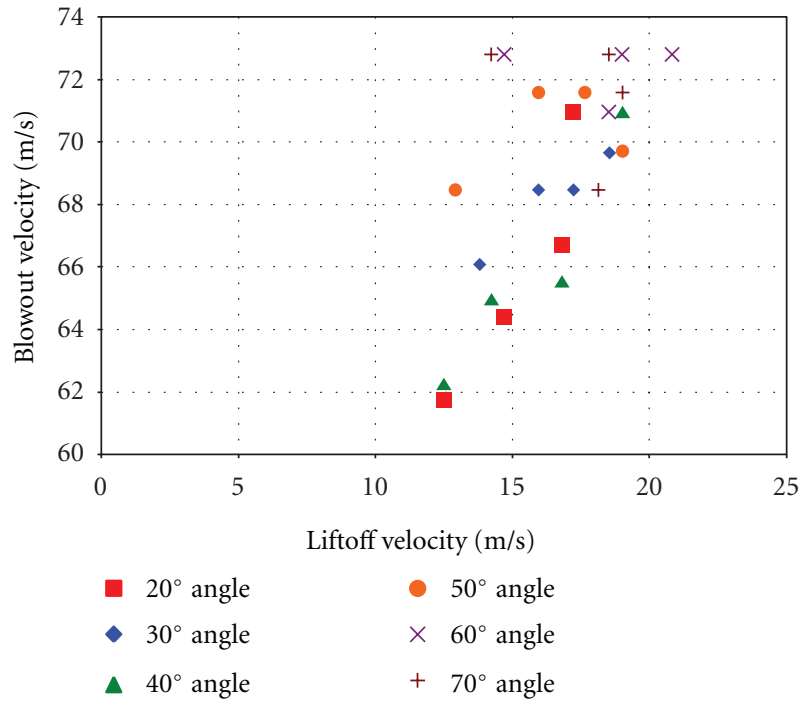

FIGURE 6: Blowout velocity versus liftoff velocity.

coflow velocity follows the equation below, as presented originally by Kalghatgi and recently by Moore et al. [11, 17]. The effective velocity depends on the fuel and air densities, as well as the ambient and coflow velocities:

$$
U_{\text {eff }}=U_{0}+C \sqrt{\frac{\rho_{\mathrm{cf}}}{\rho_{0}}} U_{\mathrm{cf}} .
$$

Lastly, the relationship between the liftoff and blowout velocities under different flow configurations can be examined. The two stability limits can be plotted against each other, as shown in Figure 6 (ignoring coflow velocity). To determine the effect of nozzle angle on the flame stability limit ratio, nondimensional analysis can be applied to the liftoff and blowout velocities. For each flow configuration, the coflow velocity is divided by the liftoff and blowout velocities to produce a dimensionless ratio. Therefore, the liftoff velocity ratio is equal to $v_{\text {coflow }} / v_{\text {jet, liftoff }}$ and the blowout velocity ratio is $v_{\text {coflow }} / v_{\text {jet, blowout }}$. These ratios were derived from the fact that the coflow velocity was limited to discrete levels, whereas the jet velocity varied. Figure 7 shows the liftoff and blowout velocity ratios plotted against each other. A strong linear relationship exists, suggesting that these two values remain in proportion to each other regardless of coflow velocity and angle.

As the results of Figure 4 suggest, there is not a strong correlation between the liftoff velocity (lower-stability limit) and flame angle. However, the angle seems to have an effect on the blowout velocity (upper-stability limit) under high coflow velocities. Figure 6 supports this notion, showing generally lower values for both liftoff and blowout velocities for higher coflow velocities. For the liftoff velocity, the effect is uniform throughout all angles. However, for the blowout velocity, the effect is more pronounced at smaller angles, namely, from $20^{\circ}$ to $40^{\circ}$. The most deviation occurs at these points.

To gain further insight, liftoff and blowout velocities are determined for flames at $90^{\circ}$ (crossflow) and $110^{\circ}$

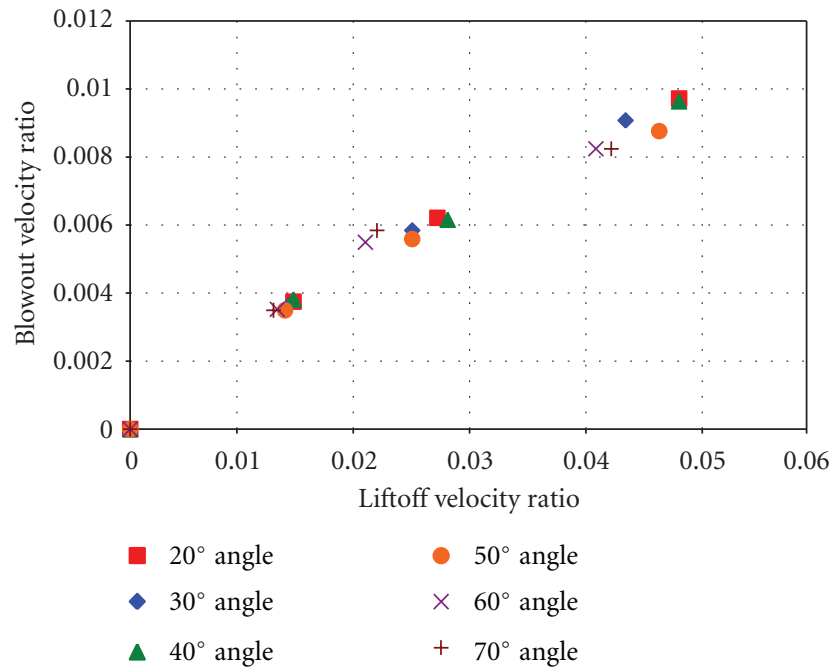

FIGURE 7: Blowout velocity ratio versus liftoff velocity ratio.

(mild counterflow). As with the previous angles, four coflow velocities are used, resulting in eight additional flow configurations. Table 2 contains the data obtained for these configurations, as well as calculated values for the liftoff and blowout velocities. Also, Figure 8 shows the crossflow and counterflow flames in their three main states: attached, lifted, and preblowout hysteresis.

Compared with the original data in Table 1, the liftoff and blowout velocities at $90^{\circ}$ and $110^{\circ}$ are greater than those for oblique angles from $20^{\circ}$ to $70^{\circ}$. These velocities can be plotted against the original data as shown in Figures 9 and 10.

Note that the blowout velocity in Figure 9 is a constant $72.80 \mathrm{~m} / \mathrm{s}$ for all eight flow configurations. This limitation occurred due to high fuel flow rates that were beyond the indicating range of the flowmeter used in this experiment. Thus, the actual blowout velocity is beyond the $72.80 \mathrm{~m} / \mathrm{s}$ reading used in Table 2 and Figure 9. Regardless, this value is still sufficient in showing that the flame upper-stability limit is generally higher for the $90^{\circ}$ and $110^{\circ}$ nozzle angles. Though the blowout velocity data is indeterminate, the liftoff velocities vary to a minimal degree with changing coflow velocities. Thus, the lower stability limit of flames in crossflow and mild counterflow is largely unaffected by coflow velocity.

Regarding Figure 1, the lower stability limit (liftoff velocity) deviates much less for the $90^{\circ}$ and $110^{\circ}$ nozzle angles. This result also indicates that coflow velocity has an inconsequential effect on crossflow and mild counterflow flames. There is an overall increase-notably at the $110^{\circ}$ nozzle angle-suggesting better stability behavior. (Again, in this case the blowout velocities remain at a maximum of $72.80 \mathrm{~m} / \mathrm{s}$ due to the limitations of the flowmeter used; the true blowout velocity is greater than this value.)

Previously, it was shown that flames at high oblique angles $\left(50^{\circ}-70^{\circ}\right)$ have higher blowout velocities that are not affected much by coflow velocity. This conclusion applies to an even greater degree for the liftoff velocities of flames at 
TABLE 2: Liftoff and blowout velocities for $90^{\circ}$ and $110^{\circ}$ flow configurations.

\begin{tabular}{lccccccc}
\hline Angle $\left({ }^{\circ}\right)$ & $\begin{array}{c}\text { Parameters } \\
\text { Coflow velocity } \\
(\mathrm{m} / \mathrm{s})\end{array}$ & Meter reading & $\begin{array}{c}\text { Liftoff } \\
\text { Chart value } \\
\left(\mathrm{ft}^{3} / \mathrm{h}\right)\end{array}$ & $\begin{array}{c}\text { Liftoff velocity } \\
(\mathrm{m} / \mathrm{s})\end{array}$ & $\begin{array}{c}\text { Meter } \\
\text { reading }\end{array}$ & $\begin{array}{c}\text { Blowout } \\
\text { Chart value } \\
\left(\mathrm{ft}^{3} / \mathrm{h}\right)\end{array}$ & $\begin{array}{c}\text { Blowout velocity } \\
(\mathrm{m} / \mathrm{s})\end{array}$ \\
\hline 90 & 0.00 & 48 & 33.8 & 19.47 & 150 & 126.4 & 72.80 \\
90 & 0.25 & 46 & 32.2 & 18.55 & 150 & 126.4 & 72.80 \\
90 & 0.40 & 47 & 33.0 & 19.01 & 150 & 126.4 & 72.80 \\
90 & 0.60 & 43 & 29.9 & 17.22 & 150 & 126.4 & 72.80 \\
110 & 0.00 & 54 & 38.6 & 22.23 & 150 & 126.4 & 72.80 \\
110 & 0.25 & 55 & 39.4 & 22.69 & 150 & 126.4 & 72.80 \\
110 & 0.40 & 57 & 41.0 & 23.61 & 150 & 126.4 & 72.80 \\
110 & 0.60 & 57 & 41.0 & 23.61 & 150 & 126.4 & 72.80 \\
\hline
\end{tabular}

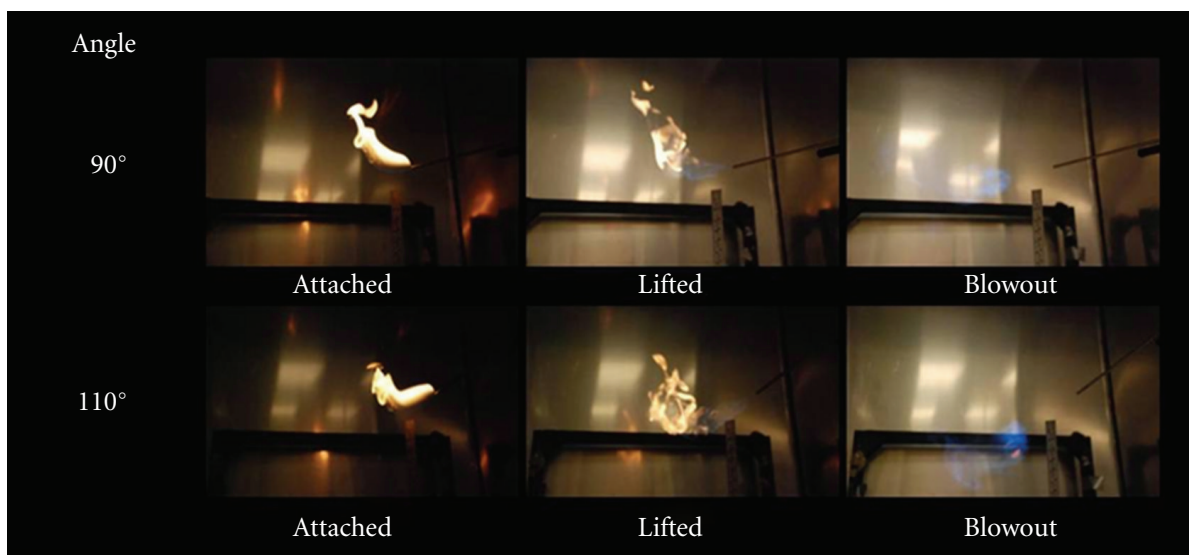

Figure 8: Flame states at high oblique angles.

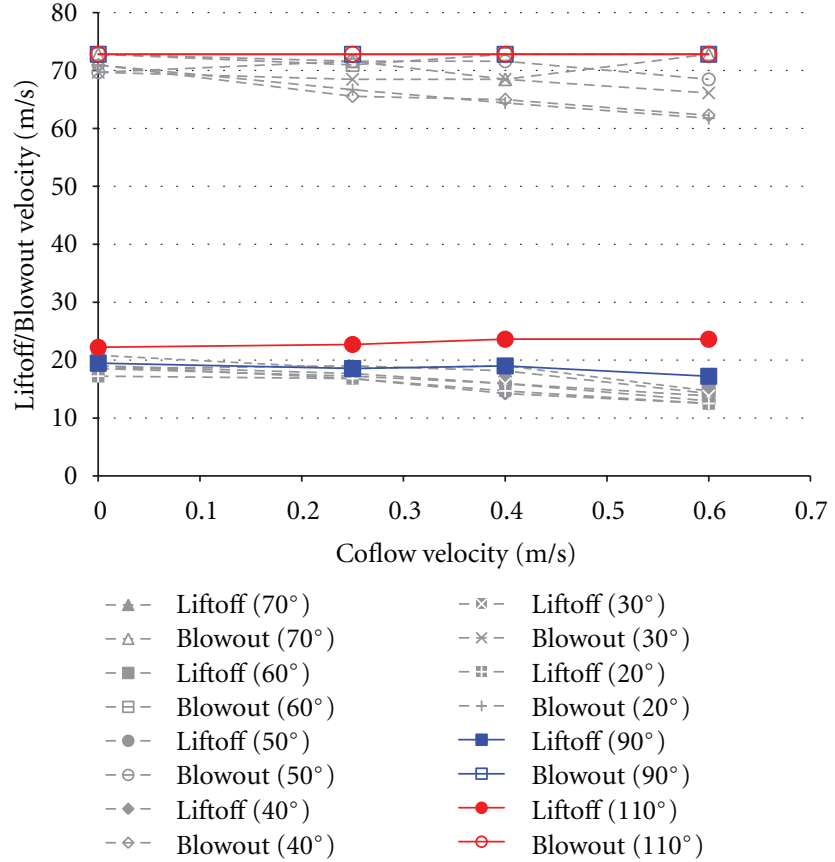

Figure 9: Stability limits versus coflow velocity including $90^{\circ}$ and $110^{\circ}$.

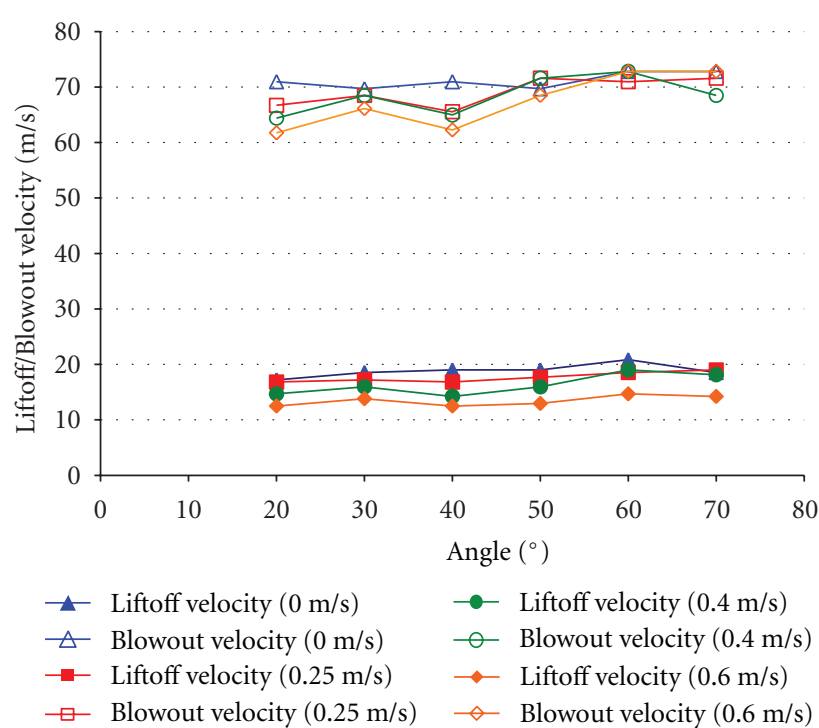

FIGURE 10: Stability limits versus angle including $90^{\circ}$ and $110^{\circ}$.

$90^{\circ}$ and $110^{\circ}$ angles, which are higher and remain nearly constant regardless of coflow velocity. Though changes in blowout velocity could not be determined, the actual values 
exceed the velocities for oblique flames in the $20^{\circ}-70^{\circ}$ range. Thus, flames in crossflow and mild counterflow have higher stability limits than those in an oblique configuration.

\section{Conclusions}

Based on the results obtained from this experiment, a number of conclusions may be drawn regarding the stability of oblique jet flames in coflow.

(1) Flame liftoff velocity is largely unaffected by the nozzle angle. However, the liftoff velocity generally decreases with increasing coflow velocity. This phenomenon is due to the coflow air contributing to the lifting of the flame, which results in a lower required fuel supply velocity (i.e., liftoff velocity).

(2) Flames at more oblique angles $\left(50^{\circ}-70^{\circ}\right)$ have a greater blowout velocity that is also more resistant to changes in coflow velocity. This behavior is due to a reduced effective coflow velocity that occurs at these angles. Overall, flames in these configurations are the most consistent in terms of upper- and lower-stability limits.

(3) A strong linear relationship exists between the non dimensional liftoff and blowout velocity ratios, which incorporate the coflow velocity. Thus, the actual liftoff and blowout velocities remain proportional to each other regardless of the coflow velocity and angle.

(4) The blowout behavior for flames in crossflow $\left(90^{\circ}\right)$ and mild counterflow $\left(110^{\circ}\right)$ cannot be determined from the data obtained. However, the same data shows that the liftoff velocity of flames in crossflow and mild counterflow is largely unaffected by coflow velocity. In general, the lower stability limits (liftoff velocities) are higher than those for oblique flames in the $20^{\circ}-70^{\circ}$ range.

This experiment served as a basic observation of how the angle between a jet flame and its surrounding flow can affect the flame stability limits. A more extensive study would be required in order to fully understand the relation between these two factors. With more measurements at different ambient flow velocities, it may be possible for a mathematical model to be developed (perhaps based on the previous work of Kalghatgi). A stronger correlation may exist under flow configurations not used in this experiment. Higher coflow velocities may be achieved with the use of a wind tunnel.

The data obtained revealed that an oblique flame in counterflow (i.e., at $110^{\circ}$ ) behaves differently than an oblique flame in coflow (between $0^{\circ}$ and $90^{\circ}$ ). Further experiments can be performed to study flames at more extreme angles, such as those between $90^{\circ}$ and $180^{\circ}$. Such work would help determine if counterflow flames can be utilized in efficient burner designs. Horizontal coflow orientations may also be investigated.

Additionally, this experiment only considered methane as the fuel source. Future experiments may be performed with propane, ethylene, hydrogen, or other commonly used hydrocarbon fuel sources. Non reacting diluents such as nitrogen can also be introduced in the fuel. Furthermore, the stabilizing effect of high coflow temperatures can be studied [18]. The equivalence ratio may be introduced as yet another parameter that can influence flame stability.

\section{Acknowledgment}

The research presented in this paper has been partially supported by the U.S. Army Research Office (Contract no. W911NF0810142), Dr. Ralph Anthenien, technical monitor.

\section{References}

[1] K. K. Kuo, Principles of Combustion, Wiley-Interscience, New York, NY, USA, 2nd edition, 2005.

[2] K. Wohl, N. M. Kapp, and C. Gazley, "The stability of open flames," Symposium on Combustion and Flame, and Explosion Phenomena, vol. 3, no. 1, pp. 3-21, 1949.

[3] L. Vanquickenborne and A. van Tiggelen, "The stabilization mechanism of lifted diffusion flames," Combustion and Flame, vol. 10, no. 1, pp. 59-69, 1966.

[4] G. T. Kalghatgi, "Lift-off heights and visible lengths of vertical turbulent jet diffusion flames in still air," Combustion Science and Technology, vol. 41, pp. 17-29, 1984.

[5] C. D. Brown, K. A. Watson, and K. M. Lyons, "Studies on lifted jet flames in coflow: the stabilization mechanism in the nearand far-fields," Flow, Turbulence and Combustion, vol. 62, no. 3, pp. 249-273, 1999.

[6] S. R. Tieszen, D. W. Stamps, and T. J. O’Hern, "A heuristic model of turbulent mixing applied to blowout of turbulent jet diffusion flames," Combustion and Flame, vol. 106, no. 4, pp. 442-466, 1996.

[7] C. P. Burgess and C. J. Lawn, "The premixture model of turbulent burning to describe lifted jet flames," Combustion and Flame, vol. 119, no. 1-2, pp. 95-108, 1999.

[8] S. Navarro-Martinez and A. Kronenburg, "Analysis of stabilization mechanisms in lifted flames," in International COST Conference on Les and DNS of Ignition Complex-Structure Flames with Local Extinction, pp. 13-38, pol, November 2008.

[9] R. V. Bandaru and S. R. Turns, "Turbulent jet flames in a crossflow: Effects of some jet, crossflow, and pilot-flame parameters on emissions," Combustion and Flame, vol. 121, no. 1-2, pp. 137-151, 2000.

[10] G. T. Kalghatgi, "Blow-out stability of gaseous jet diffusion flames part II: effect of cross wind," Combustion Science and Technology, vol. 26, no. 5-6, pp. 241-244, 1981.

[11] G. T. Kalghatgi, "Blow-out stability of gaseous jet diffusion flames part III: effect of burner orientation to wind direction," Combustion science and technology, vol. 28, no. 5 /6, pp. 241$245,1982$.

[12] D. Han and M. G. Mungal, "Simultaneous measurements of velocity and CH distribution. Part II: Deflected jet flames," Combustion and Flame, vol. 133, no. 1-2, pp. 1-17, 2003.

[13] E. F. Hasselbrink and M. G. Mungal, "Transverse jets and jet flames. Part 2. Velocity and OH field imaging," Journal of Fluid Mechanics, vol. 443, pp. 27-68, 2001.

[14] J. L. McCraw, Observations on upstream flame propagation in ignited hydrocarbon jets, M.S. thesis, Department of Mechanical and Aerospace Engineering, North Carolina State University, Raleigh, NC, USA, 2006. 
[15] S. D. Terry and K. M. Lyons, "Low Reynolds Number turbulent lifted flames in high co-flow," Combustion Science and Technology, vol. 177, no. 11, pp. 2091-2112, 2005.

[16] R. F. Huang and S. M. Wang, "Characteristic flow modes of wake-stabilized jet flames in a transverse air stream," Combustion and Flame, vol. 117, no. 1-2, pp. 59-77, 1999.

[17] N. J. Moore, J. Kribs, and K. M. Lyons, "Investigation of Jet-Flame Blowout with Lean-Limit Considerations," Flow, Turbulence and Combustion, pp. 1-12, 2011.

[18] S. Lamige, C. Galizzi, J. Min et al., "Effect of reactant preheating on the stability of non-premixed methane/air flames," in Proceedings of the International Heat Transfer Conference, Washington, DC, USA, 2010. 

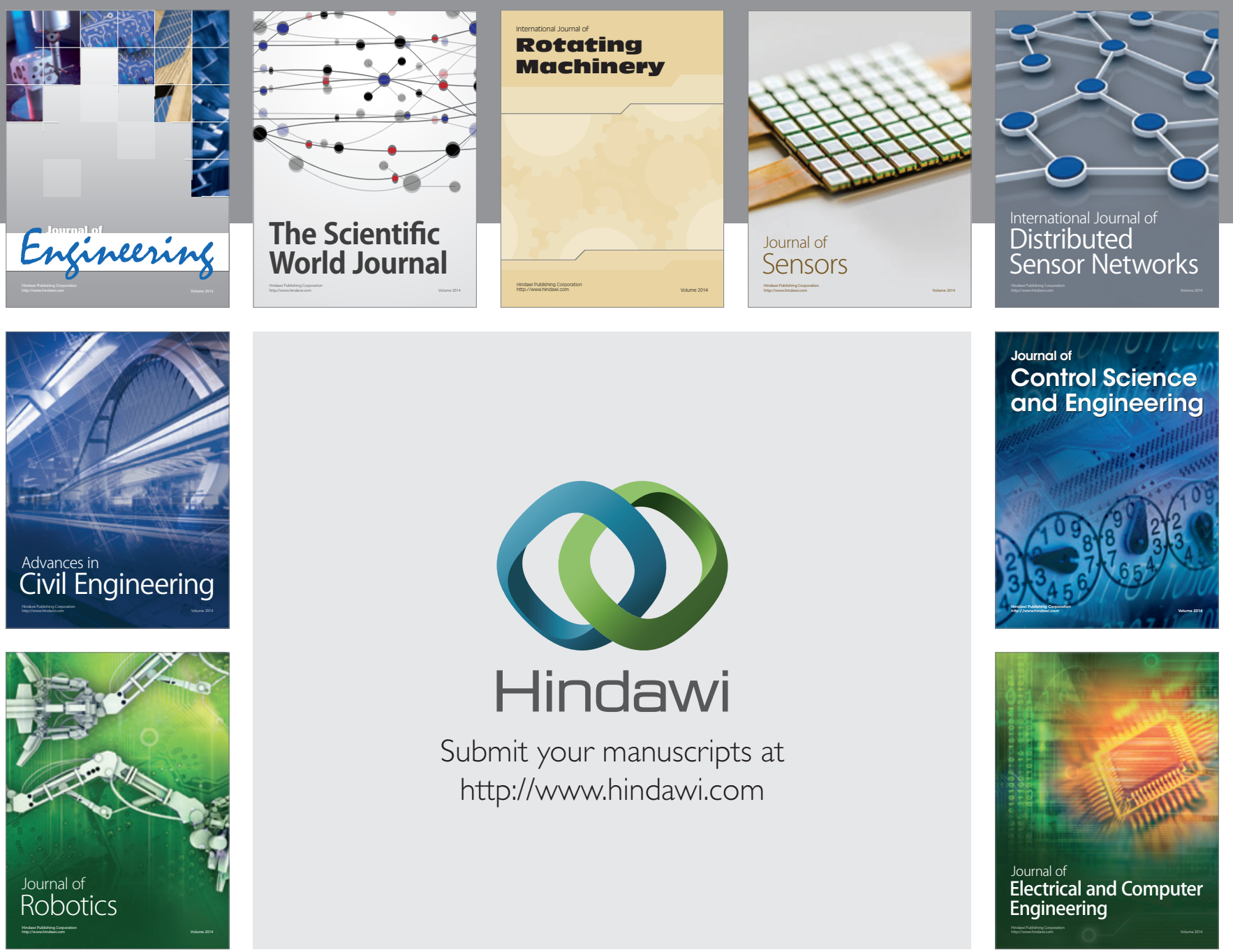

Submit your manuscripts at

http://www.hindawi.com
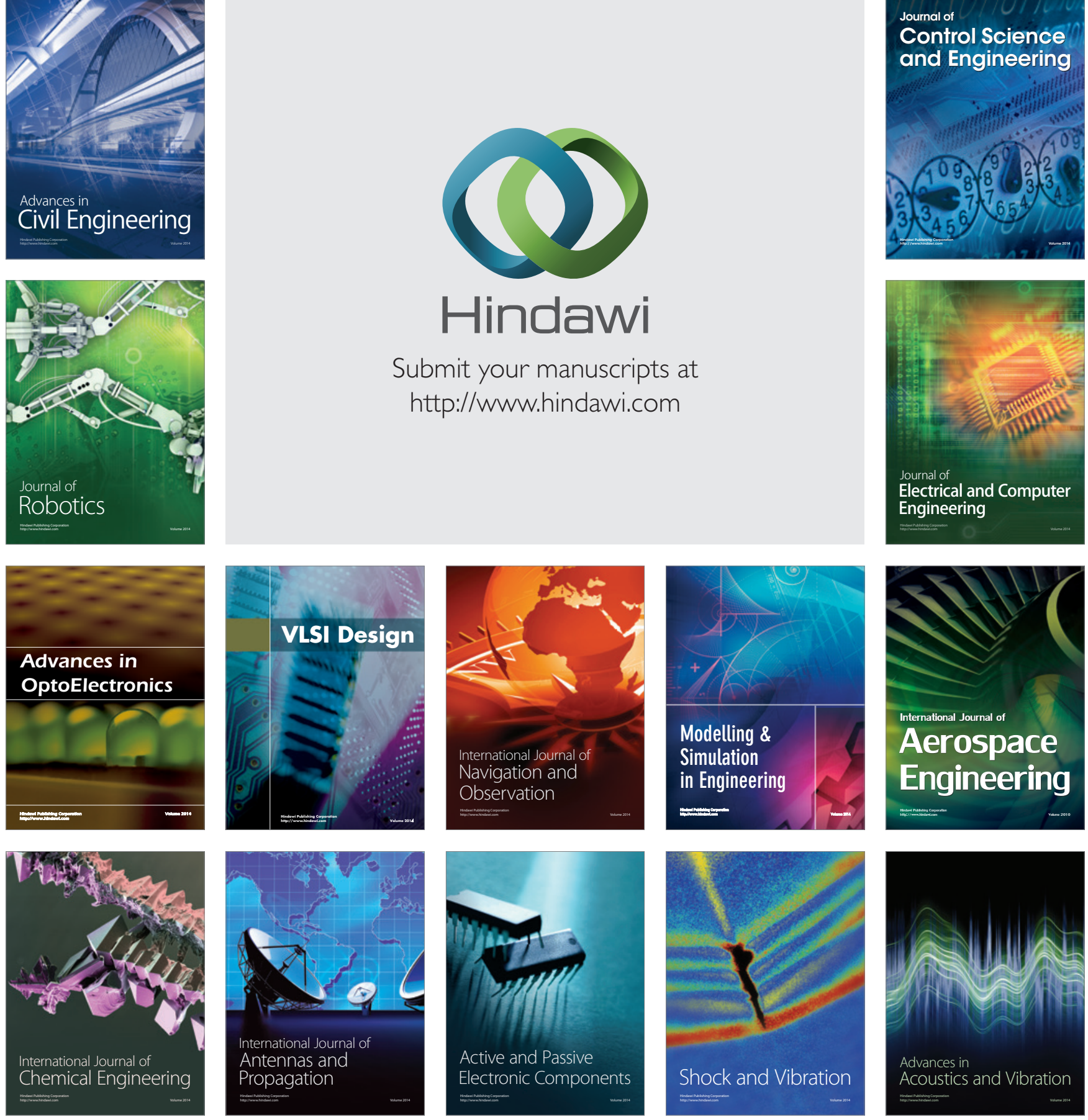